\title{
Determination of model characteristics of martial mixed arts fighters
}

\author{
Sergii Latyshev ${ }^{1 *}$, Mykola Latyshev ${ }^{2}$, Irina Tsarevskaya ${ }^{1}$, Natalia Krivtsova $^{1}$, Nikolay \\ Ryzhin $^{1}$, and Elena Nemceva ${ }^{1}$ \\ ${ }^{1}$ Don State Technical University, 344002, Rostov-on-Don, Russia \\ ${ }^{2}$ Borys Grinchenko Kyiv University, 04053, Kyiv, Ukraine
}

\begin{abstract}
The popularity of mixed martial arts(MMA) has been growing steadily and now this sport is the most striking and spectacular of martial arts. Worth millions royalties' of top fighters stimulate talented athletes to change one types of martial arts for MMA, which significantly increase the competition among athletes and qualitatively change the competitive activity. A need arises to optimize the training process in accordance with modern trends in competitive activity. The process of training will be effective only if it is built on the basis of data on the model characteristics of today's top athletes. The article defined and calculated values of the model characteristics of Top MMA fighters of Ultimate Fighting Championship (UFC). These characteristics are divided into four groups: age-anthropometric, rating, kicks performance and defense, takedowns performance and defense. The obtained data can be used when planning the training process both for young and qualified sportsmen.
\end{abstract}

\section{Introduction}

Mixed martial arts (MMA) is a combination of many techniques, schools and styles of martial arts. MMA is a full contact fighting using stroke skills and wrestling both in the stand-up and ground work position.

MMA date back to the times before Christ: the ancient Greeks in the first Olympic Games competed in Pank ration, but until the 1990s the MMA were not so popular in the world. Only with the establishment and development of organizations such as the «Ultimate Fighting Championship», «Pride Fighting Championships» and others MMA popularity began to increase sharply. Now MMA is the most striking and spectacular sport of all the arts. This is achieved by clear rules for the audience unlike other martial arts (in particular wrestling) and a combination of a large number of heavy, spectacular strikes with effective and high amplitude techniques [1].

The number of athletes involved in the sport is steadily increasing both in the world and in Russia, new specialized sports halls are opened and old wrestling and boxing halls are redesigned. Worth millions royalties of top fighters stimulate talented athletes to change one types of martial arts for MMA [2, 3].

* Corresponding author: slatyshev@ukr.net 
It is known that the athletic training of both young and qualified sportsmen will be effective only if it is organized on the basis of the model characteristics data $[4,5,6]$.

In recent years, there has been an increased interest in research related to the analysis of the characteristics of competitive activity of MMA fighters. So in the study [7], a comparative analysis of time-motion and technical-tactical behaviors of professional mixed martial arts bouts with a focus on longer bouts was carried out. Also in the work [8], a comparative time-motion analysis between weight divisions in male fighters and rounds of Mixed Martial Arts was made. The time characteristics for each weight category are considered, depending on the intensity of the fight (low or high-intensity), stand-up or groundwork position by round.

In addition to the time characteristics, the analysis of technical and tactical actions of athletes attracts the attention of researchers [9]. Thus, a technical-tactical preparation-fight analysis for athletes belonging to the elite of the Polish MMA organization was conducted and the structure and composition of athletes ' actions in combat and their effectiveness were considered [10]. It is worth noting that the work considers the top athletes who are in the leaders of the UFC rating.

The considered scientific researches cover only some aspects of competitive activity: they are conducted for different level / gender of athletes and they are not systematized and are fragmentary.

However, the account of model characteristics is necessary for individual approach to top athletes during their training $[4,6]$. So, all these factors have determined the topicality of this research.

2 Aim of research: to determine the model characteristics of highest qualification MMA fighters.

\section{Materials and methods}

Based on the above, we have selected from 13 to 15 fighters (depending on the completeness of the information about the athlete in a database on the official UFC website) with the highest rating in each UFC League weight category to determine the characteristics of the highest qualification fighter. In total, 122 fighters were selected. These fighters were divided into three weight groups. The light weight group up to $70 \mathrm{~kg}$ (weight categories $56.7 \mathrm{~kg}, 61.2 \mathrm{~kg}, 65.8 \mathrm{~kg}$ ) included 46 fighters, the medium weight group from $70 \mathrm{~kg}$ to $85 \mathrm{~kg}$ (weight categories $70.3 \mathrm{~kg}, 77.1 \mathrm{~kg}, 83.9 \mathrm{~kg}$ ) included 47 fighters and the heavy weight group over $85 \mathrm{~kg}$ (weight categories $93 \mathrm{~kg}$ and over $93 \mathrm{~kg}$ ) included 29 fighters. Then 33 indicators characterizing anthropometry, rating and particular qualities of the technical and tactical fighter skill were chosen [11].

These indicators were divided into four groups: age and anthropometric, rating, impact performance and defense, takedown performance and defense. Rating parameters and indicators of technical and tactical skills characteristics were based only on fights of the UFC league.

Age and anthropometric indicators include age, height, weight, arm and leg span. Rating indicators include UFC League ranking, the number of wins, the number of losses, the number of draws; the number of knockouts, the number of wins by decision of the judges, the number of wins by submission (the win after submission hold), the number of attempts to perform submission for 15 minutes; the average number of knockdowns of the combat; average time of the combat.

The group of the kicks performance and defense includes the following indicators: the number of discarded accented kicks in all fights; the number of supported accented kicks in 
all fights; reliability (precision) of kicks; the number of accented head kicks in all fights; the number of accented body kicks in all fights; the number of accented legs kicks in all fights; the share of reflected accented kicks; the average number of applied accented kicks per minute; the average number of accented lost kicks per minute; the average amount of applied accented kicks per fight; the number of applied stand-up accented kicks in all fights; the number of applied accented clinch kicks in all fights; the number of applied accented groundwork kicks in all fights.

Indicators of takedowns performance and defense were classified as follows: the number of attempts to perform takedowns in all fights; the number of performed takedowns in all fights; reliability of takedowns performance; reliability of takedowns defense; the average number of takedowns performed for 15 minutes.

Then, average values were calculated taking into consideration the parameters, which are averaged for model characteristics of higher qualification fighters.

For a more detailed analysis of competitive activity, we introduce the terms of activity, effectiveness and reliability of the technical actions performance. So, under the takedown activity $A_{t}$ and effectiveness $E_{t}$ we mean the number of actual attempts to perform takedowns (taking an opponent on to the ground) per unit of time and the number of achieved takedowns per unit of time, respectively. Under the activity $A_{k}$ and effectiveness $\mathrm{E}_{\mathrm{k}}$ of kicks, we mean the number of completed accented kicks per unit of time and the number of kicks applied per unit of time, respectively. Then, the takedowns and kicks reliability as the percentage will be calculated according to the formulas $\left(\mathrm{A}_{\mathrm{T}} / \mathrm{E}_{\mathrm{T}}\right) \times 100 \% \mathrm{u}$ $R_{K}=\left(A_{K} / E_{K}\right) \times 100 \%$ respectively, and the reliability of takedown $D^{t}$ and kicks defense $D_{k}$ is defined as the correlation of the amount of deflected takedowns and impacts to the total number of takedowns and kicks performed by the opponent respectively. Statistical data analysis and visualization of competitive activity data was performed using licensed MS Excel 2010.

\section{Results}

It is known that UFC League has been taking the first place in the mixed martial arts ranking for many years. Each fighter wishes for taking part in this league, and the possession of the belt can be equal to the Olympic medal. Herewith fees for fights are much higher than for medals in Olympics and in championships. Manyathletes, mostly fighters, having the world championships and Olympic Games awards sign contracts with the League $[1,11]$. This fact allows us to consider league fighters to be highly qualified and to have an extreme degree of training. Table 1 presents quantitative values of MMA fighter model characteristics.

Table 1. Quantitative values of the model characteristics of age, wins and draws for MMA fighter.

\begin{tabular}{|c|c|c|c|c|c|}
\hline \multirow[b]{2}{*}{ Characteristics } & \multicolumn{4}{|c|}{ Meaning } & \multirow[b]{2}{*}{$\begin{array}{c}\text { Units of } \\
\text { measurements }\end{array}$} \\
\hline & $\begin{array}{c}\text { Light } \\
\text { weight } \\
\text { group }\end{array}$ & $\begin{array}{l}\text { Middle } \\
\text { weight } \\
\text { group }\end{array}$ & $\begin{array}{l}\text { Heavy } \\
\text { weight } \\
\text { group }\end{array}$ & $\begin{array}{l}\text { Average } \\
\text { for all }\end{array}$ & \\
\hline $\begin{array}{l}\text { Number of } \\
\text { fighters }\end{array}$ & 46 & 47 & 29 & 122 & human \\
\hline Age & 30.3 & 31.9 & 33.9 & 31.8 & year \\
\hline Number of wins & 7.2 & 9.6 & 8.7 & 8.5 & units \\
\hline $\begin{array}{c}\text { Number of } \\
\text { losses }\end{array}$ & 2.7 & 3.5 & 3.7 & 3.3 & units \\
\hline $\begin{array}{c}\text { Number of } \\
\text { draws }\end{array}$ & 0.0 & 0.1 & 0.0 & 0.0 & units \\
\hline
\end{tabular}


Thus, the average age of a top league UFC fighter is 31.8 years old, it is a serious age for a fighter. It is explained by the fact that a fighter takes quite a long athletic way, starting as an amateur, then as a professional fighter in different leagues and finally in UFC league where a fighter tries to perform as long as possible.

For the light weight group, this age is almost 2 years less than the average, and for the heavy weight group, 2 years more. This fact is clearly confirmed by the data on the sports longevity of heavy weights $[8,12,13]$. In order to be on the list of the top 15 fighters in the league in the light weight group, a fighter must win an average of 7.2 wins with 2.7 losses; in the medium weight group, a fighter must win an average of 9.6 wins with 3.5 losses; in the heavy weight group, a fighter must win an average of 8.7 wins with 3.7 losses. These data confirm a well-known pattern observed in martial arts, namely, in the middle weight categories, the number of fighters is greater than in light or heavy, and to get into the list of the top 15 , a fighter needs to hold a greater number of fights $[3,14,15]$. Table 2 provides data on the percentage of wins, depending on the method of achieving them for each weight group, and the average value for all athletes.

Table 2. Quantitative values of the model characteristics of wins and knockdowns for MMA fighter.

\begin{tabular}{|c|c|c|c|c|c|}
\hline \multirow[b]{2}{*}{ Characteristics } & \multicolumn{4}{|c|}{ Meaning } & \multirow{2}{*}{$\begin{array}{l}\text { Units of } \\
\text { measurements }\end{array}$} \\
\hline & $\begin{array}{l}\text { Light weight } \\
\text { group }\end{array}$ & $\begin{array}{c}\text { Middle } \\
\text { weight group }\end{array}$ & $\begin{array}{c}\text { Heavy } \\
\text { weight group }\end{array}$ & $\begin{array}{r}\text { Average } \\
\text { for all } \\
\end{array}$ & \\
\hline $\begin{array}{l}\text { Percentage of } \\
\text { wins by } \\
\text { knockout }\end{array}$ & 30.5 & 44.8 & 50.5 & 40.9 & $\%$ \\
\hline $\begin{array}{l}\text { Percentage of } \\
\text { wins by judge } \\
\text { decision }\end{array}$ & 54.5 & 35.4 & 32.4 & 41.8 & $\%$ \\
\hline $\begin{array}{l}\text { Percentage of } \\
\text { wins by } \\
\text { submission }\end{array}$ & 15.0 & 19.8 & 17.1 & 17.3 & $\%$ \\
\hline $\begin{array}{l}\text { Average number } \\
\text { of knockdowns } \\
\text { per fight }\end{array}$ & 0.46 & 0.55 & 0.6 & 0.52 & units \\
\hline
\end{tabular}

To be on the list of the 15 top league fighters in each weight an athlete should take part in average 11.8 fights with 8.5 wins and 3.3 losses. At the same time $40.9 \%$ of wins are reached due to knockout (or technical knockout), and $41.8 \%$ by the judge decision. These data show that, the fighter ends on average $58.2 \%$ of combats ahead of time.

The table shows that in the heavy weight group, more than half of the fights $(50.5 \%)$ end in knockouts (or technical knockouts), in the average $44.8 \%$, and in the light only $30.5 \%$. A similar situation is observed with knockdowns, their greatest number is recorded in heavyweights ( 0.6 per fight), and the smallest in lightweights ( 0.46 per fight), despite the fact that the average fight time for heavyweights is more than 2 minutes less than for representatives of light weight categories. This pattern should be taken into account when planning the training process with fighters of different weight categories. At the same time, in the heavy weight group, $17.1 \%$ of fights end in submission, in the medium $-19.8 \%$ and in the light $-15 \%$. Thus, in the heavy weight group, more than $2 / 3$ of the fights end prematurely, and in the light weight group, less than half. This data directly affects the duration of the battle. Figure 1 shows the data on the average time of the duration of the match, depending on the weight group. 


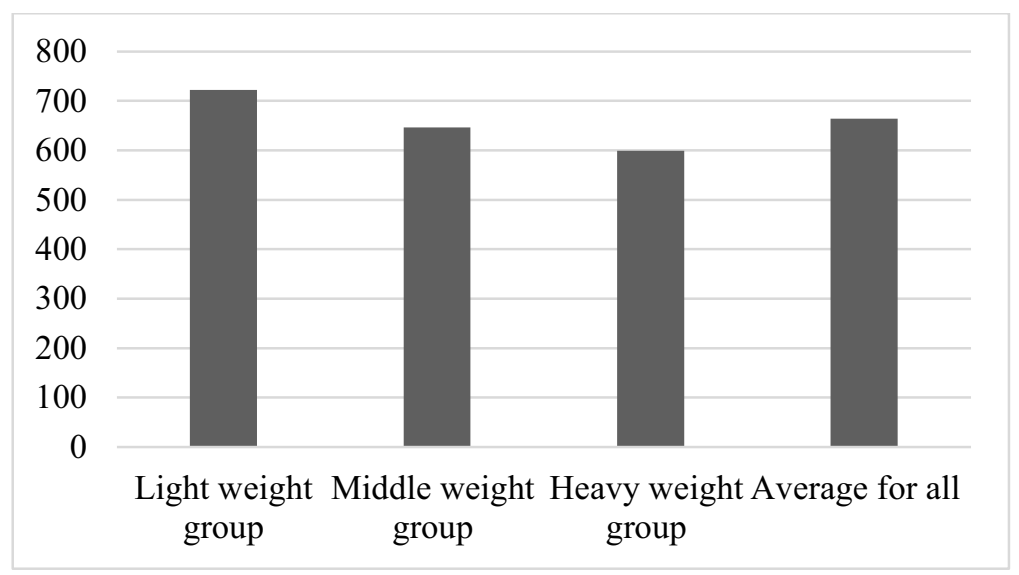

Fig. 1. The average time per fight for each weight group.

The average number of knockdowns makes up 0.52 when the average time of the fight is 11 minutes 04 seconds.

While the average time of the fight in the fighters of the heavy weight group is minimal and is 9 min. 59 seconds, in the fighters of the medium weight group this value is greater by 47 seconds, and in the light as much as $2 \mathrm{~min}$. 3seconds. There is a clear dependence of the duration of the fight on the weight category: the lower the weight category, the longer the duration of the fight. The linear regression coefficient was $3.79 \mathrm{~s} / \mathrm{kg}$. Table 3 shows the model characteristics of the activity, the effectiveness of MMA fighters ' blows delivered on average per minute, as well as the reliability of blows and the reliability of protection against them.

Table 3. Quantitative values of the model characteristics of kicks for MMA fighter.

\begin{tabular}{|c|c|c|c|c|c|}
\hline \multirow[b]{2}{*}{ Characteristics } & \multicolumn{4}{|c|}{ Meaning } & \multirow[b]{2}{*}{$\begin{array}{c}\text { Units of } \\
\text { measurements }\end{array}$} \\
\hline & $\begin{array}{l}\text { Light } \\
\text { weight } \\
\text { group }\end{array}$ & $\begin{array}{l}\text { Middle } \\
\text { weight } \\
\text { group }\end{array}$ & $\begin{array}{l}\text { Heavy } \\
\text { weight } \\
\text { group }\end{array}$ & $\begin{array}{l}\text { Average } \\
\text { for all }\end{array}$ & \\
\hline $\mathrm{A}_{\mathrm{K}}$ (Kicks activity) & 9.7 & 8.7 & 7.8 & 8.84 & units /min. \\
\hline $\begin{array}{l}\mathrm{E}_{\mathrm{K}} \text { (Kicks } \\
\text { effectiveness) }\end{array}$ & 4.0 & 4.0 & 3.9 & 3.99 & units /min. \\
\hline $\begin{array}{l}\mathrm{R}_{\mathrm{K}} \text { (Kicks } \\
\text { reliability) }\end{array}$ & 42.6 & 47.4 & 50.9 & 46.4 & $\%$ \\
\hline $\mathrm{D}_{\mathrm{K}}$ (Kicks defense) & 61.7 & 58.2 & 57.3 & 59.3 & $\%$ \\
\hline
\end{tabular}

Model characteristics of kicks performance and defense have the following meanings: the intensity and effectiveness of accented kicks constitute 8.84 and 3.99 kicks per minute respectively. The reliability of offensive and defensive kicks account for $46.4 \%$ and $59.3 \%$ respectively. It follows that less than half of accented kicks reach the goal, and 6 of 10 kicks the fighter takes in the block.

The greatest number of accented kicks is performed by the fighters of the light weight group ( 9.7 beats/min.), and the least by the heavy $(7.7$ beats $/ \mathrm{min}$.), while the effectiveness of performing accented kicks is almost the same for all weight groups and is 4 beats $/ \mathrm{min}$. From these data, it follows that the fighters of the heavy weight group have the greatest reliability of blows $(50.9 \%)$, and the least - light $(42.6 \%)$. As for the reliability of protection against accented kicks, it is approximately the same for fighters of all categories and ranges from $57.3 \%$ to $61.7 \%$. The percentage distribution of blows 
inflicted in the rack, clinch and stalls; blows to the head, body and legs is presented in Table 4.

Table 4. Quantitative values of the model characteristics of accented kicks for MMA fighter.

\begin{tabular}{|c|c|c|c|c|c|}
\hline \multirow[b]{2}{*}{ Characteristics } & \multicolumn{4}{|c|}{ Meaning } & \multirow[b]{2}{*}{$\begin{array}{c}\text { Units of } \\
\text { measurements }\end{array}$} \\
\hline & $\begin{array}{l}\text { Light } \\
\text { weight } \\
\text { group }\end{array}$ & $\begin{array}{l}\text { Middle } \\
\text { weight } \\
\text { group }\end{array}$ & $\begin{array}{l}\text { Heavy } \\
\text { weight } \\
\text { group }\end{array}$ & $\begin{array}{l}\text { Average } \\
\text { for all }\end{array}$ & \\
\hline $\begin{array}{l}\text { Percentage of } \\
\text { accented stand- } \\
\text { up kicks }\end{array}$ & 73.5 & 68.0 & 64.3 & 69.2 & $\%$ \\
\hline $\begin{array}{l}\text { Percentage of } \\
\text { accented clinch } \\
\text { kicks }\end{array}$ & 10.6 & 14.3 & 18.4 & 13.6 & $\%$ \\
\hline $\begin{array}{l}\text { Percentage of } \\
\text { accented } \\
\text { groundwork } \\
\text { kicks }\end{array}$ & 15.9 & 17.7 & 19.3 & 17.2 & $\%$ \\
\hline $\begin{array}{l}\text { Percentage of } \\
\text { accented head } \\
\text { kicks attempts }\end{array}$ & 64.5 & 65.1 & 66.8 & 65.3 & $\%$ \\
\hline $\begin{array}{l}\text { Percentage of } \\
\text { accented body } \\
\text { strikes attempts }\end{array}$ & 19.8 & 19.5 & 18.9 & 19.5 & $\%$ \\
\hline $\begin{array}{l}\text { Percentage of } \\
\text { accented leg } \\
\text { kicks attempts }\end{array}$ & 15.7 & 15.4 & 14.3 & 15.2 & $\%$ \\
\hline
\end{tabular}

In the standing position the fighter applies $69.2 \%$ of all accented kicks, in the ground position $-17.2 \%$, in the clinch - just $13.6 \%$. In this case, in the standing position the fighter performs $65.3 \%$ of the head accented kicks, $19.5 \%$ - the body accented kicks and 15.2 - the leg accented kicks.

Analyzing the distribution of kicks inflicted in the stand-up, ground and clinch, you can trace the following pattern: the greater the weight of the fighter, the more he strikes in the ground and clinch and less in the stand-up. At the same time, the greatest number of kicks is applied in the stand-up and is $73.5 \%$ for the light weight group and $64.3 \%$ for the heavy one of all the kicks thrown by the fighter.

Of all the accented kicks delivered in the stand-up, the largest number is directed to the head, on average, $65.3 \%$, while this value is practically independent of the weight group. An average of $19.5 \%$ is applied to the body and $15.2 \%$ to the legs, and these values are approximately the same for all weight groups. These data indicate the identity in the methods of technical training of fighters of all weight categories, which in our opinion is not entirely true.

Table 5 contains information on the takedown activity, effectiveness, reliability and the takedown defense reliability of athletes.

Table 5. Quantitative values of the model characteristics of takedown for MMA fighter.

\begin{tabular}{|c|c|c|c|c|c|}
\hline \multirow{3}{*}{ Characteristics } & \multicolumn{4}{|c|}{ Meaning } & Units of \\
\cline { 2 - 5 } & $\begin{array}{c}\text { Light } \\
\text { weight } \\
\text { group }\end{array}$ & $\begin{array}{c}\text { Middle } \\
\text { weight } \\
\text { group }\end{array}$ & $\begin{array}{c}\text { Heavy } \\
\text { weight } \\
\text { group }\end{array}$ & $\begin{array}{c}\text { Average } \\
\text { for all }\end{array}$ & $\begin{array}{c}\text { measurements } \\
\text { meun }\end{array}$ \\
\hline
\end{tabular}




\begin{tabular}{|l|c|c|c|c|c|}
\hline $\begin{array}{l}\mathrm{A}_{\mathrm{T}}(\text { Takedown } \\
\text { activity) }\end{array}$ & 0.314 & 0.278 & 0.269 & 0.288 & $\begin{array}{c}\text { takedowns } \\
/ \mathrm{min} .\end{array}$ \\
\hline $\begin{array}{l}\mathrm{E}_{\mathrm{T}} \text { (Takedown } \\
\text { effectiveness) }\end{array}$ & 0.103 & 0.099 & 0.106 & 0.102 & $\begin{array}{c}\text { takedowns } \\
/ \mathrm{min} .\end{array}$ \\
\hline $\begin{array}{l}\mathrm{R}_{\mathrm{T}} \text { (Takedown } \\
\text { reliability) }\end{array}$ & 33.5 & 36.2 & 36.6 & 35.3 & $\%$ \\
\hline $\begin{array}{l}\mathrm{D}_{\mathrm{T}} \text { (Takedown } \\
\text { defense reliability) }\end{array}$ & 71.7 & 69.1 & 67.9 & 69.8 & $\%$ \\
\hline
\end{tabular}

Model characteristics of takedown performance and defense have the following meanings. The takedown intensity and effectiveness constitute 0.29 and 0.10 takedowns per minute, respectively. The reliability of takedowns performance and defense constitutes $35.3 \%$ and $69.8 \%$, respectively. The high reliability of takedowns defense has been confirmed by earlier studies of elite athletes [5, 16]: Ultimate Fighting Championship combats from July to December $2014(\mathrm{n}=234)$. These data confirm the fact that to learn how to perform a technical action effectively is much more difficult than to learn how to be defended of it.

The model characteristics of take down activity and defense have the following values: the highest activity of takedowns is observed in the fighters of the light weight group and is $0.314 \mathrm{td} . / \mathrm{min}$., the lowest in the fighters of the heavy weight group- $0.269 \mathrm{td}$. / min. At the same time, the highest performance of takedowns in the fighters of the heavy weight group is $0.106 \mathrm{td} . / \mathrm{min}$., and the lowest in the average weight group is $0.099 \mathrm{td} . / \mathrm{min}$. The highest takedowns reliability is observed in the fighters of the heavy weight group and is $36.6 \%$, and the highest reliability of defense takedowns in the fighters of the light weight group and is $71.7 \%$.

\section{Discussion}

The age of the maximum peak of the results is an important factor in the planning of longterm preparation $[14,17]$. For wrestling this age is $24-26$, for Greco-Roman style European champions the age is equal to 24 years old, for champions of the world -25.6 years old, the average age of wrestling Olympic champions is of 1996-2016 - 25.5years old [12, 13]. The age of boxers, the participants of the Olympic Games [18] is 22 years old (from 17 to 34).

The studies of Kirk [3, 16] show that the age of the athletes in the national MMA championship is approximately 26.2 years old, while for the top athletes this figure is between 29 and 33 depending on the weight This study shows that the age is 31.8 years old that is significantly (older) more than in Olympic kinds of sport. This is explained by the fact that athletes pass a certain way (a series of wins) to reach the top of the rankings and can't achieve such results after one or two competitions (for example, like in the Olympic Games or the World Cup), as well as the retraining from other sports after reaching there a certain level, which demands several years [19, 20, 21].

A comparative analysis of the article showed the differences between the ways to achieve wins. In studies of Del Vecchio [2]; Coswig [22]; Miarka [8]; the following methods to achieve a win have been recorded: $57.7 \%$ of fights were ended by knockout or technical knockout, $23.1 \%$ of the fights were ended by submission or chokes attempts and $19.2 \%$ - by the judge decision. For top-ranking UFC fighters $41,8 \%$ of wins are achieved by the judge decision that indicates a high level of competition.

\section{Conclusion}


Thus, values of model characteristics of MMA fighters of higher qualification have been defined and calculated. These characteristics are classified into four groups: ageanthropometric characteristics, rating characteristics, characteristics of impact performance and defense and takedowns performance and defense. The obtained data can be used when planning the training process both for young and qualified sportsmen.

\section{Conflicts of interest}

No potential conflict of interest was reported by the authors.

\section{References}

1. Mixed martial arts. www.britannica.com (2020) [cited 1 December 2020]. Available from: https://www.britannica.com/sports/mixed-martial-arts

2. F.B. Del Vecchio, S.M. Hirata, E. Franchini, Perceptual and Motor Skills 112(2), 639648 (2011). doi:10.2466/05.25.PMS.112.2.639-648

3. C. Kirk, Facta Universitatis, series: Physical Education and Sport 16 (1),73-84 (2018). https://doi.org/10.22190/FUPES180329007K

4. L.P. James, V.G. Kelly, E.M.Beckman, Strength \& Conditioning Journal 35 (6), 34-45 (2013).

5. L.P.James, S. Robertson, G.G. Haff, E.M. Beckman, V.G. Kelly, Journal of Science and Medicine in Sport 20 (3), (2017). doi:10.1016/j.jsams.2016.08.001

6. S.V. Latyshev, G.V. Korobeynikov, Physical education of students 5, 65-68 (2013). doi:10.6084/m9.figshare.771109

7. B. Miarka, V.S. Coswig, J. Amtmann, International Journal of Performance Analysis in Sport 19 (2), 153-166 (2019).

8. B. Miarka, V.S. Coswig, F.B. Del Vecchio, C.J. Brito, J. Amtmann, International Journal of Performance Analysis in Sport 15 (3), 1189-1201 (2015). doi:10.1080/24748668.2015.11868861

9. B. Miarka, V. Coswig, J.C. Brito, M. Slimani, J. Amtmann, F.B. Del Vecchio, International Journal of Performance Analysis in Sport 16 (2), 539-552 (2016).

10. M. Adam, R. Pujszo, S. Kuźmicki, M. Szymański, S. Tabakov, Journal of Combat Sports and Martial Arts 6(1), 35-41 (2015).

11. UFC. Athlete Rankings. www.ufc.com (2020). [cited 1 December 2020]. Available from:https://www.ufc.com/rankings

12. M.Biac, K.Hrvoje, D.Sprem,Kinesiology 46 (S-1), 94-100 (2014)

13. M.Latyshev,S.Latyshev, G.Korobeynikov, O.Kvasnytsya, V.Shandrygos, Y.Dutchak, Journal of Human Sport and Exercise 15(2), 400-410 (2020) doi:https://doi.org/10.14198/jhse.2020.152.14

14. C.A. Bridge, M.A. Jones, B. Drust, International Journal of Sports Physiology and Performance 6 (3), 344-357 (2011). doi:10.1123/ijspp.6.3.344.

15. L.P. James, G.G. Haff, V.G. Kelly, E.M. Beckman, Sports Medicine 46 (10), 15251551 (2016). doi:10.1007/s40279-016-0493-1.

16. C. Kirk, H.T. Hurst, S. Atkins, International Journal of Performance Analysis in Sport 15 (1), 359-370 (2015). doi:10.1080/24748668.2015.11868798.

17. S.V. Allen, W.G. Hopkins, Sports Medicine 45 (10), 1431-1441 (2015). 
18. S. Neselius, H. Brisby, A. Theodorsson, K. Blennow, H. Zetterberg, PLoS ONE 7 (4), e33606 (2012). doi:10.1371/journal.pone.0033606

19. J.J. Silva, F.B. Del Vecchio, L.M. Picanço, M.Y. Takito, E. Franchini, Journal of Human Sport and Exercise 6 (3), 490-496 (2011). doi:10.4100/jhse.2011.63.02

20. M. Tabben, J. Coquart, H. Chaabène, E. Franchini, N. Ghoul, C. Tourny, Journal of Sports Sciences 33:8, 841-849 (2015). doi: 10.1080/02640414.2014.965192

21. G.V. Korobeynikov, S.V. Latyshev, N.V. Latyshev, A.U. Goraschenko, L.G. Korobeynikova, Physical Education of Students 1, 37-42 (2016). doi:10.15561/20755279.2016.0105

22. V.S. Coswig, S.P. Ramos, F.B. Del Vecchio, The Journal of Strength and Conditioning Research 30 (8), 2156-2163 (2016). doi:10.1519/JSC.0000000000001340 